\title{
Estimation of Interfacial Tension in Mixtures of Linear Hydrocarbons and Immiscible Organic Liquids with Water by Dissipative Particle Dynamics (DPD)
}

\author{
Carolina Del Valle Silva ${ }^{1, *}$, Fernando Ruette ${ }^{2}$ \\ ${ }^{1}$ Institute of Venezuelan Petroleum Technology, Los Teques, Venezuela \\ ${ }^{2}$ Laboratory of Computational Chemistry, Venezuelan Institute of Scientific Research, Altos de Pipe, Venezuela \\ Email address: \\ silvach@pdvsa.com (C.D. V. Silva), carolinasil@gmail.com (C. D. V. Silva), fruette@ivic.gob.ve (F. Ruette), \\ fruette@gmail.com (F. Ruette) \\ ${ }^{*}$ Corresponding author
}

\section{To cite this article:}

Carolina Del Valle Silva, Fernando Ruette. Estimation of Interfacial Tension in Mixtures of Linear Hydrocarbons and Immiscible Organic Liquids with Water by Dissipative Particle Dynamics (DPD). International Journal of Fluid Mechanics \& Thermal Sciences.

Vol. 4, No. 1, 2018, pp. 1-10. doi: 10.11648/j.ijfmts.20180401.11

Received: February 19, 2018; Accepted: March 8, 2018; Published: March 28, 2018

\begin{abstract}
Petroleum systems have a high level of complexity due to the presence of a huge variety of organic compounds, mainly hydrocarbons. These characteristics, not only make difficult its recovery but also its study. In this sense, the study of parameters, such as the local variation of interfacial tension (IFT) is essential to understanding the behavior of different interfaces that arise through the extraction, transport and oil refining processes. Accordingly, in the present study, theoretical estimations of IFTs of linear-hydrocarbon-water, linear-hydrocarbon-glycerol, and mixtures of 11 types of organic-liquid with water were performed. The system elements were built by using coarse-graining technique and the dynamics were carried out by the Dissipative Particle Dynamics (DPD). With this technique was possible to reproduce, in a systematic way, an important set of IFT values for systems of oil industrial interest, which reproduced trends obtained from experimental analogous conditions.
\end{abstract}

Keywords: Interfacial Tension, Linear Hydrocarbons, Organic Liquids, Coarse-Graining Dissipative Particle Dynamics

\section{Introduction}

The studies of parameters, such as the local variation of interfacial tension (IFT), are of great relevance to understand the behavior of complex fluids, such as colloids, emulsions, polymers, and petroleum systems which are a multiphase fluid. Currently, an important part of developments and technological proposals in this area are focused on the IFT reduction, which is exhibited in petroleum systems upon contact with the chemical additives used for oil extraction, transport, and enhancement $[1,2]$.

In the case of oilfield fluids, these materials are mixtures composed mainly of hydrocarbons and other organic compounds which have a wide range of sizes, shapes and molecular weight distribution. The atomic content in weight for carbon ranges from $83 \%$ to $87 \%$, for hydrogen of $10 \%$ to $14 \%$, with the presence, in lower concentrations, of nitrogen, oxygen, and metals, such as $\mathrm{Na}, \mathrm{Ni}, \mathrm{V}$, and $\mathrm{Ca}[1,2]$.

Extraction, transport, and refining processes comprise complex multiphase fluids, which represents countless challenges in the different processing stages. Hence, the importance of the design methodological and numerical proposals focused on the study of the interfacial behaviors is indeed relevant.

Many investigations have dealt with the characterization and estimation of the IFT of oil/water and solvents/water because of its relevance for chemistry, biology, petroleum industry and technology areas. In this sense, Goebel et al. [3] investigated and reported IFT experimental values in dependence on time for water $/ n$-alkane from $\mathrm{C}_{5}$ to $\mathrm{C}_{14}$ and $\mathrm{C}_{16}$ at a $\mathrm{T}$ of $22^{\circ} \mathrm{C}$. López de Ramos et al. [4] measured the IFT for water $/ n$-alkane from $\mathrm{C}_{6}$ to $\mathrm{C}_{12}$ at $\mathrm{T}$ between $10^{\circ} \mathrm{C}$ to $60^{\circ} \mathrm{C}$. Furthermore, Wiegand et al. [5] used the pendant drop to measure IFT between water and non-polar fluids at $\mathrm{T}$ of 


\section{$24.85^{\circ} \mathrm{C}$ to $199.858^{\circ} \mathrm{C}$ and $\mathrm{P}$ of 1 bar to 3000 bar.}

Experimental IFT of 10 normal alkanes with water and two type of brine were measured by Guao Tian Min et al. [6] using a pendant drop instrument, where the $\mathrm{T}$ and $\mathrm{P}$ ranges were $(25 \text { to } 80)^{\circ} \mathrm{C}$ and (1 to 300$)$ bar, respectively. While, Modarress et al. [7] applied a DPD mesoscopic molecular simulation method to investigate the IFT of hydrocarbon (linear-alkanes, cycloalkane, and aromatics) with water systems. In order to study the interfacial properties, Rivera et al. [8] carried out direct molecular dynamics simulations of the liquid-liquid interface of water-methanol- $n$-alkane systems, and water- $n$-alkane from $\mathrm{C}_{5}$ to $\mathrm{C}_{10}$.

The experimental IFT values for $\mathrm{C}_{7}$, toluene, and benzene with water at the $\mathrm{T}$ range of 20 to $80^{\circ} \mathrm{C}$ were reported by Alpbaz et al. [9]. DPD technique was also used by Majumdar et al. [10] to estimate the IFT for liquid-liquid systems, such as water and glycerol with alkanes from $\mathrm{C}_{5}$ to $\mathrm{C}_{13}$ at a $\mathrm{T}$ of $25^{\circ} \mathrm{C}$, water with chloroform at a $\mathrm{T}$ of $20^{\circ} \mathrm{C}$, and benzene, bromobenzene and iodobenzene at a $\mathrm{T}$ of $25^{\circ} \mathrm{C}$. In this sense, R. David [11] reported and calculated IFT values for immiscible liquid-liquid systems among them glycerol with hydrocarbons.

Ghatee et al. [12] carried out experimental measurements of the IFT for systems of alkanes, heptanol and hexanoic acid with water, at a $\mathrm{T}$ and $\mathrm{P}$ range of (298-333) $\mathrm{K}$ and (0.8410.844 ) atm, with highly accurate results. The IFT of nitrobenzene, benzene, toluene, bromobenzene, iodobenzene, and cyclohexane systems were reported by Demond et al. [13]. Moreover, Muijlwijk et al. [14] disclosed experimental values of IFT for glycerol/water under different conditions at a $\mathrm{T}$ of $20^{\circ} \mathrm{C}$. In addition, Andersson et al. [15] evaluated the IFT between water and a set of non-polar oils used a first principle model, based on density functional theory combined with the COSMO-RS implicit solvent model. Another source of IFTs is the NPTEL web [16], which presents, in Module 2 of Lecture 2, an important list of IFT experimental values between water and immiscible organic liquids.

In general, as well as for oil/water and organic liquids/water systems, it can be observed that there is in the literature a wide range of value variations from either theoretically or experimentally estimated IFT. This means, there is a significant dispersion of the reported values in an extensive diversity of papers.

Because of the above, in the present work were calculated in a systematic way an important set of IFT for systems of technological interest. In this sense, IFT values were calculated for 3 types of systems: (a) linear hydrocarbon and water mixtures, (b) linear hydrocarbon and glycerol mixtures, and (c) organic liquids with water. Calculations were carried out at mesoscopic scale, applying the DPD simulation method using the coarse-graining technique. An algorithm focused on the IFT estimation for petroleum fluid mixtures was developed, in order to implement and to validate the code. The systems were selected based on experimentally available data for Hansen solubility parameters and experimental IFT values.
This work is organized in the following way. A brief theoretical description of DPD methodology is given in the next Section, together with a model of coarse-graining and Flory-Huggins interaction parameters. In addition, models of liquid mixtures including conditions for dynamic simulations, values of Hansen solubility, and interaction parameters. A discussion of results is presented in Section 3 considering linear-hydrocarbon-water mixtures at 22 and $50^{\circ} \mathrm{C}$, linear-hydrocarbon-glycerol mixtures at 20 and $23^{\circ} \mathrm{C}$, and organic-liquid-water mixtures at $20^{\circ} \mathrm{C}$. Finally, the last section describes the most relevant results and future work by considering more complex systems that simulate heavy oil. Thus, IFTs were systematically estimated for 44 systems of mixtures and results are compared with the theoretical and experimental data reported in the literature.

\section{Methodology}

\subsection{DPD Method}

The DPD simulation method used for mesoscopic studies was introduced by Hoogerbrugge and Koelman in 1992, as a technique oriented on the complex fluids and hydrodynamics phenomena research [17]. The development and foundation of this method were implemented by Español and Warren in 1995 [18, 19]. The DPD basic algorithm was generated by them in very similar way to that implemented in the molecular dynamics technique (MD), in the sense that particles interacting through certain forces. However, unlike to $\mathrm{MD}$, dissipative and random forces are incorporated and the system evolves with greater time steps than in the MD.

DPD fluid is composed of a set of point particles in the continuous space, and the particle's motion is governed by Newton's equations.

$$
\begin{aligned}
\frac{d \overrightarrow{r_{i}}}{d t} & =\overrightarrow{v_{i}} \\
\frac{d \overrightarrow{p_{i}}}{d t} & =\sum_{i \neq j} \overrightarrow{F_{i j}}
\end{aligned}
$$

The $F_{i j}$ are interparticle forces, which are pairwise additive and act on the line joining between particle centers. These are central forces that satisfy Newton's third law, preserving the linear and angular momentum. Three contributions are present in these forces: conservative $\left(F_{i j}{ }^{C}\right)$, random $\left(F_{i j}{ }^{D}\right)$, and dissipative $\left(F_{i j}{ }^{R}\right)$.

$$
\overrightarrow{F_{i j}}=\sum_{i \neq j}\left(\overrightarrow{F_{i j}^{C}}+\overrightarrow{F_{i j}^{D}}+\overrightarrow{F_{i j}^{R}}\right)
$$

The first term corresponds to the conservative force and it acts as a repulsive soft potential. In this work, the Eq. 4 is used for expressing the conservative force $[17,20]$ : 


$$
\overrightarrow{F_{i j}^{C}}=\left\{\begin{array}{rr}
a_{i j}\left(1-\frac{r_{i j}}{r_{C}}\right) \hat{r}_{i j}, & \left(r_{i j}<r_{C}\right) \\
0, & \left(r_{i j} \geq r_{C}\right)
\end{array}\right.
$$

where, $\overrightarrow{r_{i j}}=\overrightarrow{r_{i}}-\overrightarrow{r_{j}}, \quad r_{i j}=\left|\overrightarrow{r_{i j}}\right|, \quad \hat{r}_{i j}=\vec{r}_{i j}|| \overrightarrow{r_{i j}} \mid, \hat{r}_{i j}$ is the unit vector in the direction of $\overrightarrow{r_{i j}}$, and $r_{C}$ the cutoff radio. The $a_{i j}$ parameter is referred as the DPD interaction parameter, which depends on the underlying atomistic interactions and represents the maximum repulsion between particles.

The dissipative forces, defined by the second term in Eq. 3, represents the frictional forces that depend on both the positions $\overrightarrow{r_{i j}}$ and relative velocities $\left(\overrightarrow{v_{i j}}=\overrightarrow{v_{i}}-\overrightarrow{v_{j}}\right)$ of particles. Its intensity is regulated by the dissipation coefficient $(\gamma)$, and its range is weighted by function $w^{D}$ (rjj), as shown Eq. 5 .

$$
\overrightarrow{F_{i j}^{D}}=-\gamma w^{D}\left(r_{i j}\right)\left(\hat{r}_{i j} \cdot v_{i j}\right) \hat{r}_{i j}
$$

The third term in Eq. 3 defines the random force, necessary to maintain the system temperature, expressed in Eq. 6 as:

$$
\overrightarrow{F_{i j}^{R}}=\sigma w^{R}\left(r_{i j}\right) \theta_{i j} \hat{r}_{i j}
$$

where, $\sigma$ determines the magnitude of the random force between DPD-particles, $w^{R}(\mathrm{rjj})$ represents the random force variation with the distance and $\theta_{i j}$ is the aleatory contribution.

DPD particles are considered as groups of molecules or atoms of the fluid, as schematically shown in Figure 1. They do not represent individual molecules or atoms within the system; each one describes the position and momentum of a region of the fluid. This coarse-graining construction of the system allows a mesoscopic scale description [21, 22].

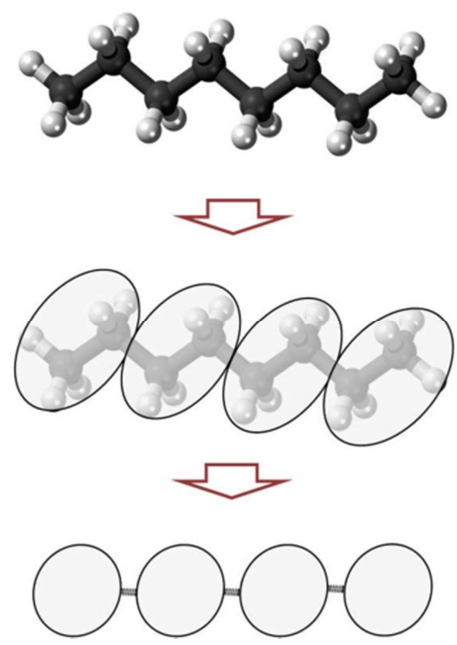

Figure 1. An n-octane coarse-graining $\left(\mathrm{C}_{8} \mathrm{H}_{18}\right)$ scheme from Silva [2].
The Groot and Warren approach [23] was used in this research, complemented by the Maiti and McGrother method [20], which establishes a connection between DPD theory, Flory-Huggins interaction parameter $\left(\chi_{i j}\right)$, and the Hansen solubility parameter $\left(\delta_{H}\right)$ [24], according to Eqs. 7 and 8 .

$$
\chi_{i j}=2 \alpha \rho\left(a_{i j}-a_{i i}\right)
$$

where, $\alpha$ is a constant about 0.1 and $\rho$ is the average density. The $\chi_{i j}$ parameters are usually estimated from the theoretical or experimental solubility parameters values, from different species belonging to the system to be studied. In this work the following expression is used:

$$
\chi_{i j}=\frac{V_{b}}{K_{B} T}\left(\delta_{i}-\delta_{j}\right)^{2}
$$

where, $\mathrm{KB}$ is the Boltzmann constant, $\delta_{i}$ and $\delta_{j}$ are solubility parameters for $i$ and $j$ species, and $\mathrm{Vb}$ is the average volume sets for all system particles and $T$ is the temperature. As can be observed, the choice or estimation of the solubility parameters is crucial to ensure the correct system simulation.

\subsection{Model of Liquid Mixtures}

In this study, an algorithm for the IFT estimation in crude oil systems was developed, with which systems of great technological interest were evaluated. The criterion for the selection of the systems was based on the availability of Hansen solubility parameters $\left(\delta_{H}\right)$ and IFT experimental data (IFT_REF) of reported values, in order to make comparisons, where REF represent the number of the cited reference.

To do this, two types of linear hydrocarbon mixtures were generated from the n-pentane $\left(\mathrm{C}_{5} \mathrm{H}_{12}\right)$ up to nhexadecane $\left(\mathrm{C}_{16} \mathrm{H}_{34}\right)$, identified as $\mathrm{C}_{5}, \mathrm{C}_{6}, \mathrm{C}_{7}, \mathrm{C}_{8}, \mathrm{C}_{9}, \mathrm{C}_{10}$, $\mathrm{C}_{11}, \mathrm{C}_{12}, \mathrm{C}_{13}, \mathrm{C}_{14}, \mathrm{C}_{15}$ y $\mathrm{C}_{16}$. In the first type, the linear hydrocarbons with water, the IFT was estimated under two $\mathrm{T}$ conditions of 20 and $50^{\circ} \mathrm{C}$. In the second type of mixtures (with glycerol), the $\mathrm{T}$ was set at 20 and $23^{\circ} \mathrm{C}$. Additionally, 11 aqueous mixture systems were studied at a $\mathrm{T}$ of $20^{\circ} \mathrm{C}$ with the organic liquids: ethyl acetate (Etact), $n$-butyl acetate (nBact), nitrobenzene (Ntrbz), chloroform (Chlorf), glycerol (Gly), benzene (Benz), toluene (Tol), bromobenzene (Brmbenz), methanol (Meth), iodobenzene (Ibenz), and cyclohexane (Clhx).

An example of the application of the coarse-graining technique for the system $n$-pentane-water is illustrated in Figure 2. Here, all the atoms that make up the $n$-pentane $\left(\mathrm{C}_{5} \mathrm{H}_{12}\right)$ were grouped into a particle called $\mathrm{C}_{5}$. In the water case, each particle of water (W) groups three water molecules. The right side of Figure 2 displays the density profile, which presents a statistic concentration for each particle type on axis $\mathrm{X}$ direction (perpendicular to the interface). 


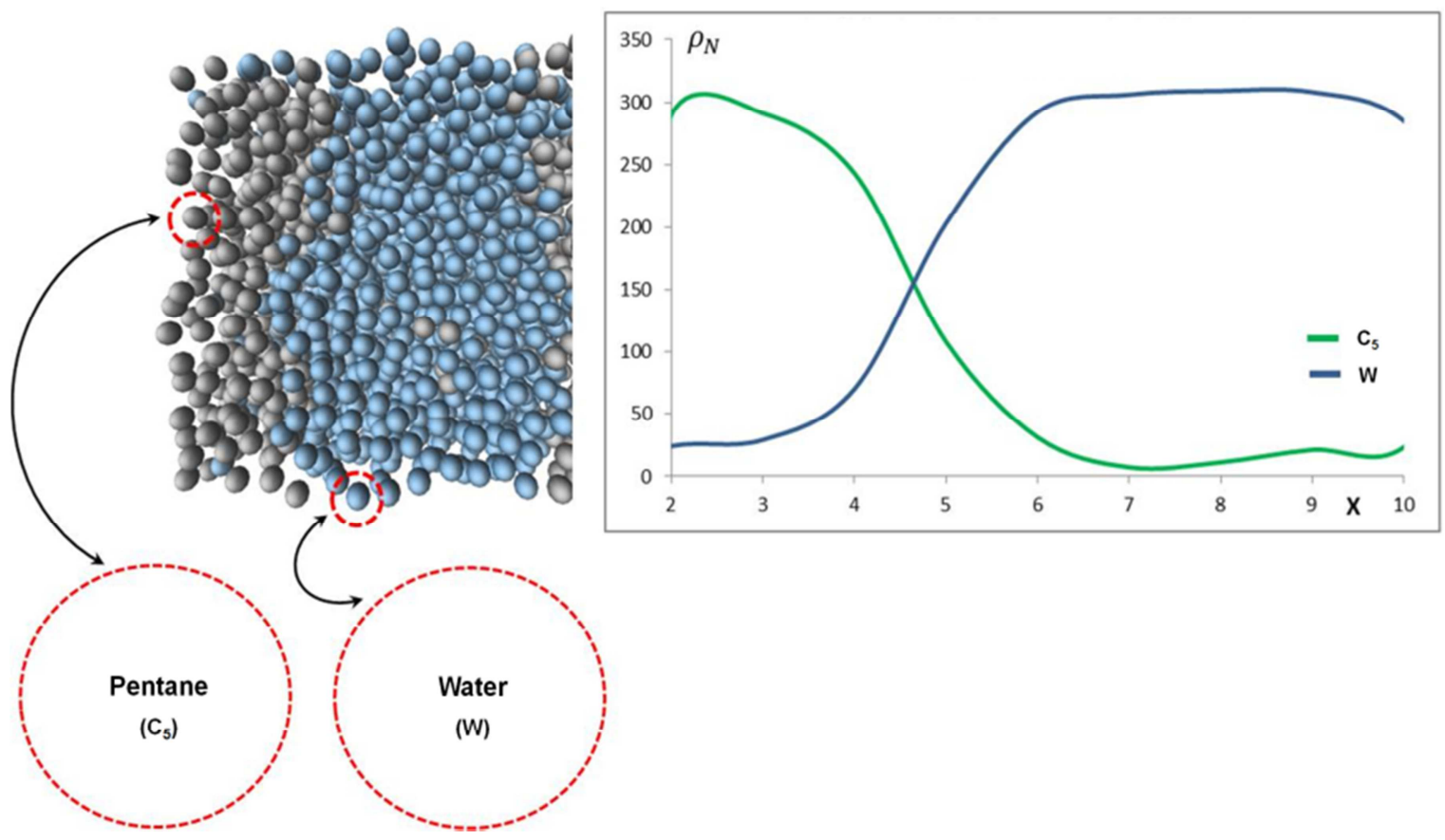

Figure 2. Coarse-graining and density profile $\left(\rho_{N}\right)$ of a pentane (C5) with water (W) mixture system at a temperature of $22^{\circ} \mathrm{C}$.

All models are confined systems, with periodic boundary conditions. To carry out the simulations, the DPD time step was set at 0.01 (DPD units) and, before starting the dynamics, in order to stabilize each system was performed 10000 steps of DPD dynamics. All dynamics were run with 300000 DPD steps. The systems consist of 3500 DPD particles made up of $40 \%$ linear hydrocarbons and $60 \%$ water for the first, $40 \%$ linear hydrocarbons and $60 \%$ glycerol for the second, and $40 \%$ organic liquid and $60 \%$ water for the third type of mixtures.

For the calculation of the different interaction of species, the experimental $\delta_{H}[25,26]$, listed in Tables 1 and 2 , were used.

Table 1. The experimental Hansen solubility parameters $\left(\delta_{H}\right)$ used to calculate linear-hydrocarbon DPD interaction parameters, $a_{i j}[24,25]$.

\begin{tabular}{ll}
\hline Compounds & $\boldsymbol{\delta}_{\boldsymbol{H}}\left(\mathbf{J} / \mathrm{cm}^{3}\right)^{1 / 2}$ \\
\hline $\mathrm{W}$ & 47.9 \\
$\mathrm{C}_{5}$ & 14.4 \\
$\mathrm{C}_{6}$ & 14.9 \\
$\mathrm{C}_{7}$ & 15.3 \\
$\mathrm{C}_{8}$ & 15.5 \\
$\mathrm{C}_{9}$ & 15.6 \\
$\mathrm{C}_{10}$ & 15.7 \\
$\mathrm{C}_{11}$ & 15.8 \\
$\mathrm{C}_{12}$ & 15.9 \\
$\mathrm{C}_{13}$ & 16.0 \\
$\mathrm{C}_{14}$ & 16.2 \\
$\mathrm{C}_{16}$ & 16.3 \\
\hline
\end{tabular}

Table 2. The experimental Hansen solubility parameters $\left(\delta_{H}\right)$ used to calculate DPD interaction parameters for organic liquid compounds, $a_{i j}$ $[25,26]$.

\begin{tabular}{ll}
\hline Compounds & $\boldsymbol{\delta}_{\boldsymbol{H}}\left(\mathrm{J} / \mathrm{cm}^{3}\right)^{1 / 2}$ \\
\hline Benz & 18.43 \\
Brmbenz & 20.78 \\
Clhx & 18.78 \\
\hline
\end{tabular}

\begin{tabular}{ll}
\hline Compounds & $\boldsymbol{\delta}_{\boldsymbol{H}}\left(\mathbf{J} / \mathbf{c m}^{3}\right)^{1 / 2}$ \\
\hline Chlrf & 18.9 \\
Etact & 16.42 \\
Gly & 34.12 \\
Meth & 19.75 \\
nBact & 16.22 \\
Ntrbz & 20.56 \\
Tol & 18.04 \\
Ibenz & 20.45 \\
\hline
\end{tabular}

With these experimental data, the Flory-Huggins values $\left(\chi_{i j}\right)$ were obtained, which are used to calculate the DPD interaction parameters, listed in Table 3.

Table 3. The DPD interaction parameters $\left(a_{i j}\right)$ of linear hydrocarbons $\left(C_{n}\right.$, $n=5$-16) with water $(W)$ and glycerol (Gly), and organic-liquid-water mixtures.

\begin{tabular}{llllll}
\hline $\mathbf{C}_{\mathrm{n}}-\mathbf{W}$ & $\boldsymbol{a}_{\boldsymbol{i j}}$ & $\mathbf{C}_{\mathrm{n}}$-Gly & $\boldsymbol{a}_{\boldsymbol{i j}}$ & Organic liquids-W & $\boldsymbol{a}_{\boldsymbol{i j}}$ \\
\hline $\mathrm{C}_{5}-\mathrm{W}$ & 38.63 & $\mathrm{C}_{5}$-Gly & 29.81 & Eact-W & 37.04 \\
$\mathrm{C}_{6}-\mathrm{W}$ & 38.23 & $\mathrm{C}_{6}$-Gly & 29.56 & nBact-W & 37.19 \\
$\mathrm{C}_{7}-\mathrm{W}$ & 37.91 & $\mathrm{C}_{7}$-Gly & 29.38 & Ntrbz-W & 34.08 \\
$\mathrm{C}_{8}-\mathrm{W}$ & 37.75 & $\mathrm{C}_{8}$-Gly & 29.28 & Chlrf-W & 35.22 \\
$\mathrm{C}_{9}-\mathrm{W}$ & 37.68 & $\mathrm{C}_{9}$-Gly & 29.24 & Gly-W & 27.31 \\
$\mathrm{C}_{10}-\mathrm{W}$ & 37.60 & $\mathrm{C}_{10}$-Gly & 29.19 & Benz-W & 35.55 \\
$\mathrm{C}_{11}-\mathrm{W}$ & 37.52 & $\mathrm{C}_{11}$-Gly & 29.15 & Tol-W & 35.83 \\
$\mathrm{C}_{12}-\mathrm{W}$ & 37.44 & $\mathrm{C}_{12}$-Gly & 29.1 & Brmbenz-W & 33.94 \\
$\mathrm{C}_{13}-\mathrm{W}$ & 37.36 & $\mathrm{C}_{13}$-Gly & 29.06 & Meth-W & 34.63 \\
$\mathrm{C}_{14}-\mathrm{W}$ & 37.21 & $\mathrm{C}_{14}$-Gly & 28.97 & Clhx-W & 34.15 \\
$\mathrm{C}_{16}-\mathrm{W}$ & 37.13 & $\mathrm{C}_{16}$-Gly & 28.92 & Ibenz-W & 35.30 \\
\hline
\end{tabular}

The interaction values, $a_{i j}$, were employed to calculate the pressure tensor components, $p_{\beta \alpha}$, which were used to calculate the IFT from DPD, according to the Eq. 9 [20].

$$
I F T_{-} D P D^{*}=L_{\beta}\left[\left\langle p_{\beta \beta}\right\rangle-\frac{1}{2}\left(\left\langle p_{\alpha \beta}\right\rangle+\left\langle p_{\alpha^{\prime} \beta}\right\rangle\right)\right]
$$


where $<\ldots>$ indicates the ensemble average of the pressure tensor components; $L_{\beta}$ is the longitudinal direction where the interface is located. The pressure tensor, $p_{\alpha \beta}$, was calculated from the conservative forces, $F_{i j}^{C}$, and the virial theorem. Theoretical IFT values (IFT_DPD*) were brought to experimental IFT units (IFT_DPD) by the expression [20]:

$$
I F T_{-} D P D=\frac{K_{B} T}{r_{C}^{2}} I F T_{-} D P D^{*}
$$

\section{Results and Discussion}

This work focused on IFT values estimations through the construction of linear hydrocarbon, water, and organic liquids mixtures mesoscopic models. In this regard, 2 types of linear hydrocarbon $\left(\mathrm{C}_{n}\right)$ mixtures were modeled. The first with water, setting $\mathrm{T}$ of the system at 22 and $50^{\circ} \mathrm{C}$. The second with glycerol at $\mathrm{T}$ of $20^{\circ} \mathrm{C}$ for linear hydrocarbons from $\mathrm{C}_{6}$ to $\mathrm{C}_{9}, \mathrm{C}_{11}, \mathrm{C}_{13}, \mathrm{C}_{14}$ and $\mathrm{C}_{16}$, and at $\mathrm{T}$ of $23^{\circ} \mathrm{C}$ for the rest $\left(\mathrm{C}_{5}\right.$, $\mathrm{C}_{10}$, and $\mathrm{C}_{12}$ ). Additionally, 11 mixtures of water with organic liquids were modeled, setting the $\mathrm{T}$ of systems at $20^{\circ} \mathrm{C}$.

In the case of linear hydrocarbons, mixtures were generated in a ratio of $40 \% \mathrm{C}_{n}$ and $60 \% \mathrm{~W}$. In the water and organic liquids mixtures, the proportion used was $40 \% \mathrm{~W}$ and $60 \%$ of organic liquid. In the graphs, each point on the curve represents the IFT system estimated value. In order to have IFT reference values with which to compare the accuracy and the trends of the IFT DPD values, considering

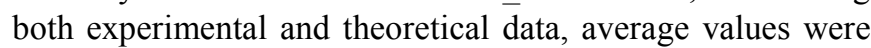
calculated, identified as IFT_PROM. The reported error and standard deviation were calculated from the IFT_PROM.

In the graphs that follow (Figure 3-6), the indexes used for theoretical and experimental references indicate the source from which was obtained; for example, IFT_1 means that the reference comes from reference 1 . There are also references designated as IFT_6_1, IFT_6_2, IFT_10_1, IFT_10_2 and IFT_11_2, indicate that values that end in 1 are evaluated by the author and values ending in 2 , the IFT results are cited by the author.

Values of IFT reflect the differences in chemical structure of the two phases involved, to a lower tendency to interact, indicates a higher IFT. For hydrocarbons-water mixtures set at a $\mathrm{T}$ of $22^{\circ} \mathrm{C}$, the IFT_DPD values compared to the IFT_REF values reported $[3,4,5,6,7,8,9,10]$ are shown in Figure 3, and the comparison between IFT_DPD and IFT_PROM values are displayed in Table 4.

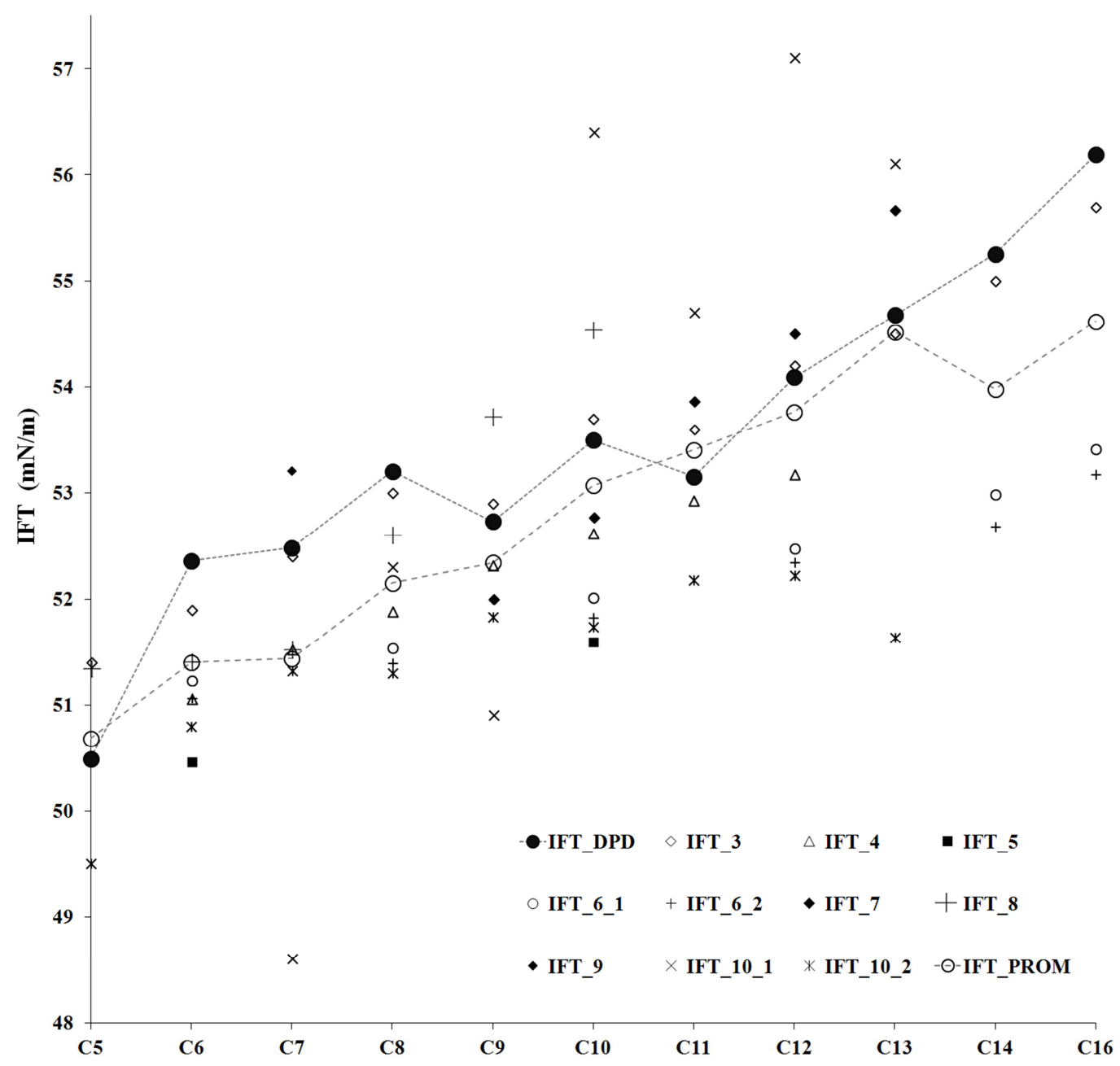

Figure 3. IFT_DPD and IFT_PROM values of linear-hydrocarbon-water mixtures at a set T of $22^{\circ} \mathrm{C}$, compared with IFT_REF obtained from the literature [3, $4,5,6,7,8,9,10]$. 
Table 4. Estimated IFT values (IFT_DPD), averages (IFT_PROM), standard dispersion ( $\sigma)$, and error rate (\% Error) respect to IFT_PROM, of linearhydrocarbon-water mixtures at $22^{\circ} \mathrm{C}$.

\begin{tabular}{lllll}
\hline $\mathbf{C}_{\mathbf{n}}$ - & IFT_DPD & IFT_PROM & $\boldsymbol{\sigma}$ & \%Error \\
\hline $\mathrm{C}_{5}$ & 49.99 & 50.18 & 0.14 & 0.38 \\
$\mathrm{C}_{6}$ & 51.86 & 50.90 & 0.68 & 1.89 \\
$\mathrm{C}_{7}$ & 51.98 & 50.94 & 0.74 & 2.04 \\
$\mathrm{C}_{8}$ & 52.70 & 51.65 & 0.73 & 2.03 \\
$\mathrm{C}_{9}$ & 52.23 & 51.84 & 0.28 & 0.75 \\
$\mathrm{C}_{10}$ & 52.99 & 52.57 & 0.30 & 0.80 \\
$\mathrm{C}_{11}$ & 52.65 & 52.90 & 0.18 & 0.47 \\
$\mathrm{C}_{12}$ & 53.59 & 53.26 & 0.23 & 0.62 \\
$\mathrm{C}_{13}$ & 54.18 & 54.02 & 0.11 & 0.30 \\
$\mathrm{C}_{14}$ & 54.75 & 53.48 & 0.90 & 2.37 \\
$\mathrm{C}_{16}$ & 55.69 & 54.12 & 1.11 & 2.91 \\
\hline
\end{tabular}

In all cases is necessary to consider that part of the experimental and theoretical IFT data consulted is not available for the same target temperature used in this work, although very close to this value; most of the temperature values of the consulted references were available for $25^{\circ} \mathrm{C}$. In the reference 6 , the IFTs were evaluated under pressure conditions upper to those of this work (1 atm). On the other hand, the $\delta_{H}$ experimental values reported were obtained under similar temperature conditions to set for the simulations.

Taking into account the above considerations, IFT_DPD

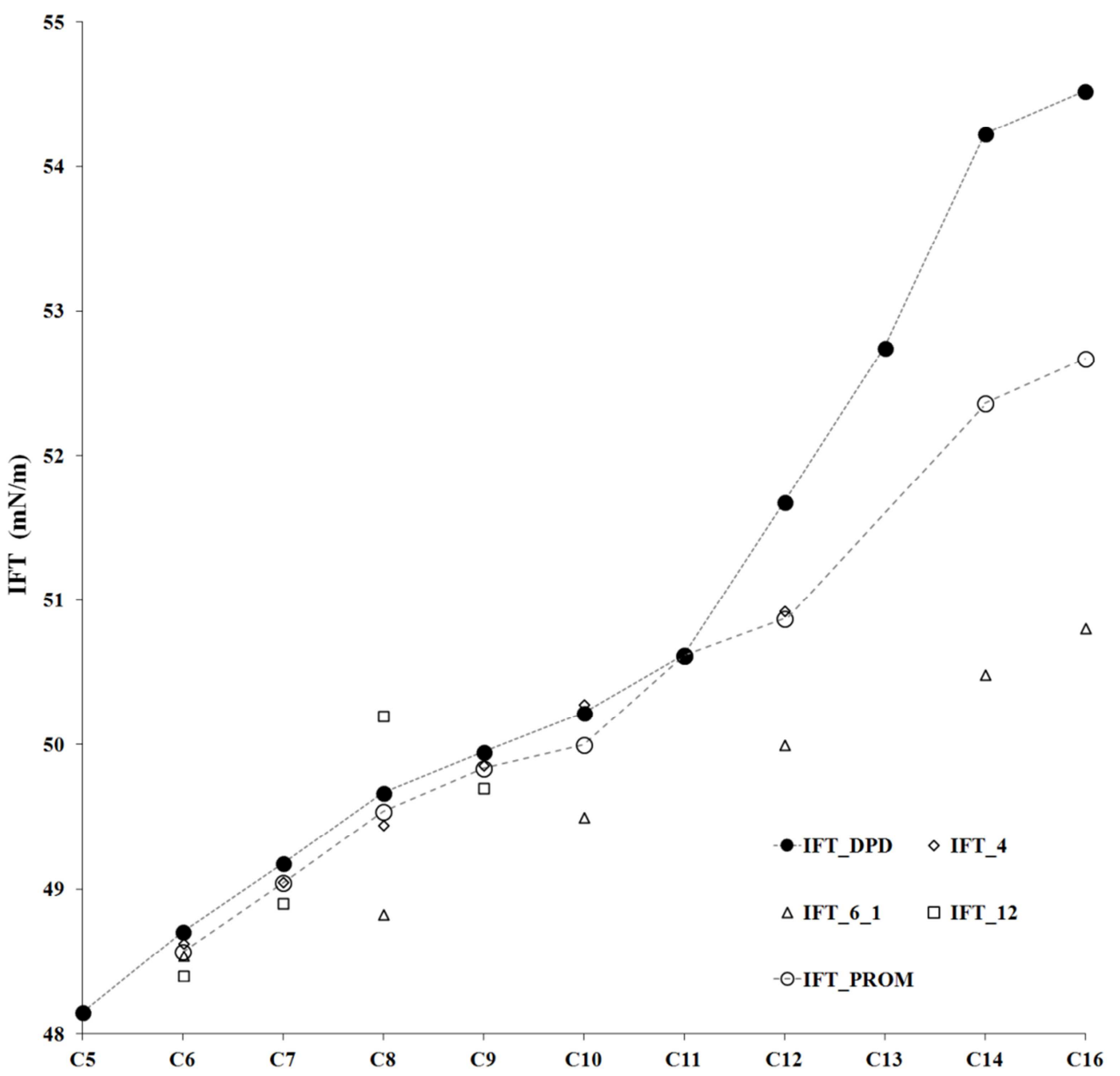

Figure 4. IFT_DPD values of linear-hydrocarbon-water mixtures at a set $T$ of $50^{\circ} \mathrm{C}$ of temperature compared with IFT_REF given in the literature [4, 6, 12]. results from simulations closely follow the increasing IFT tendency in relation to the length of the linear hydrocarbon; that is in accordance with both, the experimental and theoretical values in the consulted literature, as well as with the average IFT values calculated.

The greater uncertainty and highest error rate were found for the $\mathrm{C}_{14}-\mathrm{W}$ and $\mathrm{C}_{16}-\mathrm{W}$ mixtures, for which fewer experimental and theoretical values were available in order to contrast the estimated values. For $\mathrm{C}_{6}, \mathrm{C}_{7}$ and $\mathrm{C}_{8}$-water mixture there is about $2 \%$ error, such that the values are slightly higher than literature values, see Table 4 . These deviations are attributed to the fact of the experimental IFT values were calculated at a temperature of $25^{\circ} \mathrm{C}$, greater than the set $\mathrm{T}$ of $22^{\circ} \mathrm{C}$, yielding IFT_DPD values slightly higher.

In general, the IFT_DPD estimated values for linearhydrocarbons-water mixtures, correspond very closely with the theoretical an experimental IFT values trend, reported in the literature under similar conditions.

Figure 4 displays the experimental IFT REF values [4, 6, 12] with respect to the theoretical for hydrocarbon-water mixtures at $\mathrm{T}$ set at $50^{\circ} \mathrm{C}$. In this case, from $\mathrm{C}_{6}$ to $\mathrm{C}_{11}$ the results and experimental data are consistent with a relative error of less than $1 \%$. From $\mathrm{C}_{12}$ to $\mathrm{C}_{16}$, the IFT $D P D$ values gradually deviate from the experimental and IFT_PROM values. 
For these systems, it must be taken into account that the experimental IFT data reported by Guo et al. [6] were calculated under a $P$ range of 36.45 to $42.54 \mathrm{~atm}$, upper to pressure target used in this work of $1 \mathrm{~atm}$. This difference in the $\mathrm{P}$ conditions is reflected in the deviation among IFT DPD estimated and IFT REF [6], which has increased by increasing the alkane chain length. Besides, the $\delta_{H}$ experimental values used to calculate the Flory-Huggins values were obtained at a lower T conditions than set for the simulations, which is believed to affect the accuracy of the results.

Note that the IFT_DPD estimated values resulting from these simulations were performed with small systems (3500 particles), in short periods of time, by using a moderate performance equipment. However, even considering the differences with some of the experimental conditions, the results follow the same general tendency, both of the IFT_PROM calculated, as IFT_REF reported in the literature. That means, that IFT values increase with the increment of the $n$-alkane chain length, displayed in Table 5.

Table 5. Estimated IFT values (IFT_DPD), averages (IFT_PROM), standard dispersion $(\sigma)$, and error rate (\% Error) respect to IFT_PROM for linearhydrocarbon-water mixtures at $50^{\circ} \mathrm{C}$.

\begin{tabular}{lllll}
\hline $\mathbf{C}_{\mathbf{n}}$-W & IFT_DPD & IFT_PROM & $\boldsymbol{\sigma}$ & \% Error \\
\hline $\mathrm{C}_{5}$ & 47.65 & & & \\
$\mathrm{C}_{6}$ & 48.21 & 48.07 & 0.09 & 0.27 \\
$\mathrm{C}_{7}$ & 48.65 & 48.54 & 0.10 & 0.29 \\
$\mathrm{C}_{8}$ & 49.17 & 49.04 & 0.09 & 0.27 \\
$\mathrm{C}_{9}$ & 49.45 & 49.34 & 0.08 & 0.22 \\
\hline
\end{tabular}

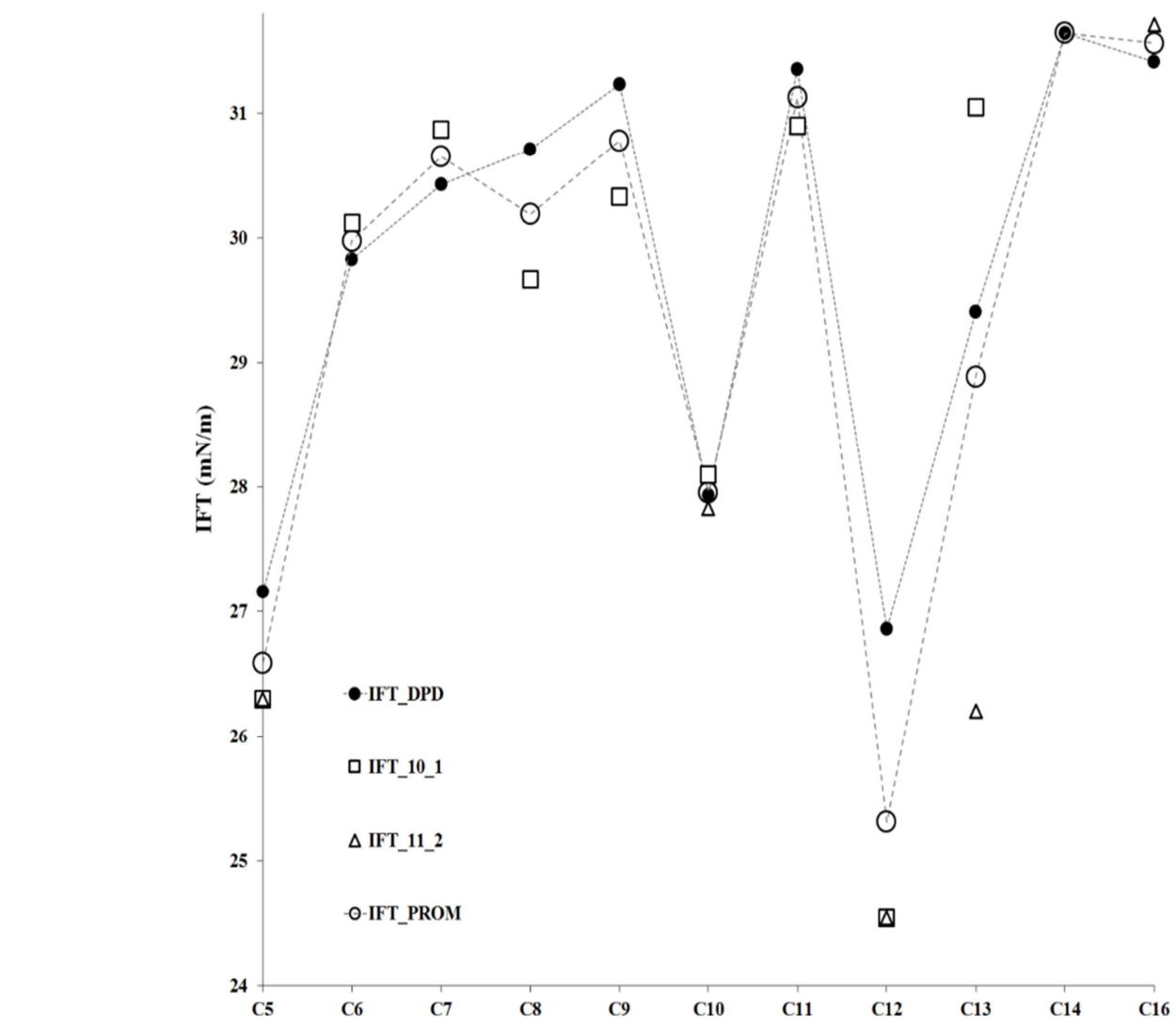

\begin{tabular}{lllll}
\hline $\mathbf{C}_{\mathbf{n}}-\mathbf{W}$ & IFT_DPD & IFT_PROM & $\boldsymbol{\sigma}$ & \% Error \\
\hline $\mathrm{C}_{10}$ & 49.72 & 49.50 & 0.16 & 0.44 \\
$\mathrm{C}_{11}$ & 50.12 & 50.14 & 0.01 & 0.04 \\
$\mathrm{C}_{12}$ & 51.18 & 50.37 & 0.57 & 1.61 \\
$\mathrm{C}_{13}$ & 52.25 & & & \\
$\mathrm{C}_{14}$ & 53.73 & 51.86 & 1.32 & 3.61 \\
$\mathrm{C}_{16}$ & 54.03 & 52.19 & 1.30 & 3.53 \\
\hline
\end{tabular}

The Figure 5 and Table 6 shows the IFT_DPD and IFT_PROM calculated values of linear-hydrocarbons and glycerol mixtures compared to IFT_REF $[10,11]$. In this case, $\mathrm{C}_{5}, \mathrm{C}_{10}$, and $\mathrm{C}_{12}$ systems were calculated at $20^{\circ} \mathrm{C}$, and the rest of the mixtures at $23^{\circ} \mathrm{C}$.

Table 6. Estimated IFT values (IFT_DPD), averages (IFT_PROM), standard dispersion ( $\sigma)$, and error rate (\% Error) respect to IFT PROM, of linearhydrocarbon-glycerol mixtures at $20^{\circ} \mathrm{C}$ for $C_{5}, C_{10}$, and $C_{12}^{-}$, and $23^{\circ} \mathrm{C}$ for the rest.

\begin{tabular}{lllll}
\hline $\mathbf{C}_{\mathbf{n}}$-Gly & IFT_DPD & IFT_PROM & $\boldsymbol{\sigma}$ & \% Error \\
\hline $\mathrm{C}_{5}$ & 27.36 & 26.79 & 0.41 & 2.10 \\
$\mathrm{C}_{6}$ & 30.03 & 30.18 & 0.11 & 0.48 \\
$\mathrm{C}_{7}$ & 30.63 & 30.85 & 0.16 & 0.72 \\
$\mathrm{C}_{8}$ & 30.91 & 30.39 & 0.37 & 1.68 \\
$\mathrm{C}_{9}$ & 31.43 & 30.98 & 0.32 & 1.43 \\
$\mathrm{C}_{10}$ & 28.13 & 28.15 & 0.02 & 0.08 \\
$\mathrm{C}_{11}$ & 31.55 & 31.33 & 0.16 & 0.70 \\
$\mathrm{C}_{12}$ & 27.06 & 25.51 & 1.10 & 5.72 \\
$\mathrm{C}_{13}$ & 29.60 & 29.08 & 0.37 & 1.75 \\
$\mathrm{C}_{14}$ & 31.84 & 31.84 & & \\
$\mathrm{C}_{16}$ & 31.61 & 31.76 & 0.11 & 0.47 \\
\hline
\end{tabular}

Figure 5. IFT_DPD values of linear-hydrocarbon-glycerol mixtures at a set $T$ of $20^{\circ} \mathrm{C}$ to $C 5, C 10$ and $C 12$, and $23^{\circ} \mathrm{C}$ of $T$ for the rest, compared with IFT_REF given in the literature $[10,11]$. 
Once again, IFT_DPD estimated values showed a tendency very similar to those found at the experimental level. The IFT_DPD values for this type of mixtures reproduced on average the experimental behavior reported from $\mathrm{C}_{5}$ to $\mathrm{C}_{13}$ and $\mathrm{C}_{16}$. The theoretical values presented for $\mathrm{C}_{14}$ is a prediction of the trend of IFT_REF values, under analogous conditions.

An interesting point was found for the $\mathrm{C}_{12}$-glycerol system, in which it was observed a significant decrease in the IFT value, both for the theoretically calculated value and the experimental value reported $[10,11]$. One assumption is that this IFT value behavior is due to a geometric rearrangement as has been reported by Byrd et al. [26] for $n$-alkanes greater $\mathrm{C}_{11}$.

The IFT_DPD results obtained for immiscible organic liquids against water mixtures, compared to IFT_REF values $[5,10,13,14,15,16,27]$ are given in Table 7 and Figure 6.

Once again, it can be observed that IFT_DPD estimations and the relative variations between them are quite similar to the IFT_REF values reported and the average values calculated, IFT_PROM. The greatest deviation and relative error were obtained for the Etact-W and Chlrf-W mixtures.

In the case of Etact-W mixture, the calculated value of IFT was $9,78 \mathrm{mN} / \mathrm{m}$, higher than experimental value [15] of the $6,80 \mathrm{mN} / \mathrm{m}$, which was reported at $25^{\circ} \mathrm{C}$, while the IFT DPD values were calculated at $20^{\circ} \mathrm{C}$. The difference between temperatures, the error involved in modeling the Etact molecule as a single particle, and the approach to consider this liquid as a non-polar solvent, could be part of the observed differences between these values.

For the Chlrf-W mixture, the result obtained for IFT was $28.2 \mathrm{mN} / \mathrm{m}$, lower than 31.6 [16], 34.0 [10], and 32.8 [27] $\mathrm{mN} / \mathrm{m}$, theoretical and experimental values reported in the literature. However, the first two were evaluated at $25^{\circ} \mathrm{C}$ while the last at $20^{\circ} \mathrm{C}$. In this case, the difference between the IFT values is mainly attributed to model simplifications. Nevertheless, there are good IFT estimated values, taking into account that these fluid elements are represented by single particles.

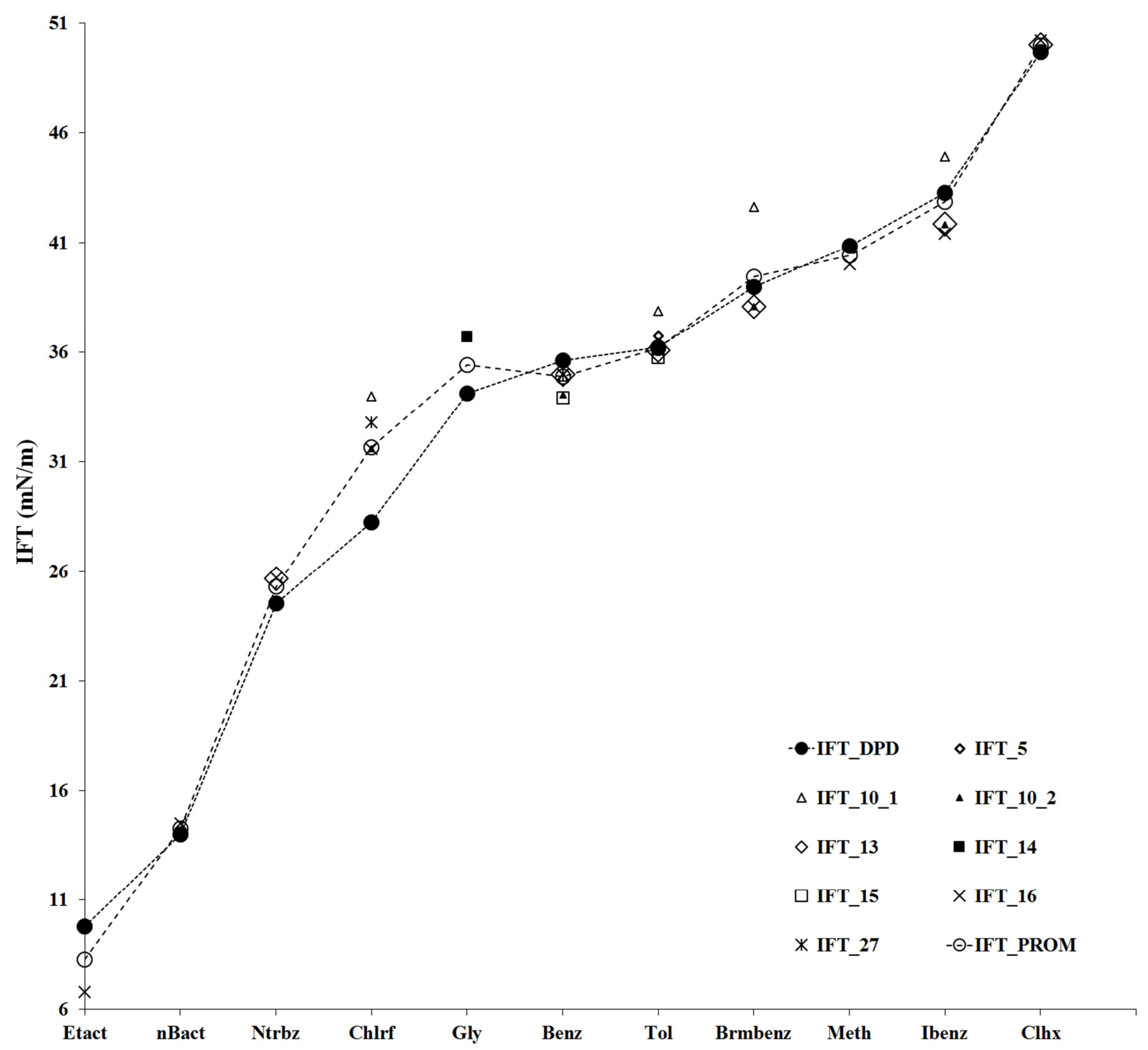

Figure 6. IFT_DPD values of organic-liquid-water mixtures at a set $T$ of $20^{\circ} \mathrm{C}$, compared with IFT_REF consulted in the literature [5, 10, 13, 14, 15, 16, 27]. 
Table 7. Estimated IFT values (IFT_DPD), averages (IFT_PROM), standard dispersion $(\sigma)$ and error rate (\% Error) respect to IFT_PROM for organicliquid-water mixtures at $20^{\circ} \mathrm{C}$.

\begin{tabular}{lllll}
\hline W-organic liquids & IFT_DPD & IFT_PROM & o & \% Error \\
\hline Etact & 9.78 & 8.29 & 1.05 & 17.97 \\
nBact & 13.98 & 14.24 & 0.18 & 1.83 \\
Ntrbz & 24.55 & 25.30 & 0.53 & 2.96 \\
Chlrf & 28.23 & 31.66 & 2.43 & 10.83 \\
Gly & 34.12 & 35.41 & 0.91 & 3.64 \\
Benz & 35.62 & 34.91 & 0.50 & 2.03 \\
Tol & 36.23 & 36.18 & 0.04 & 0.14 \\
Brmbenz & 38.99 & 39.45 & 0.33 & 1.17 \\
Meth & 40.84 & 40.42 & 0.30 & 1.04 \\
Ibenz & 43.23 & 42.84 & 0.28 & 0.91 \\
Clhx & 49.67 & 49.96 & 0.21 & 0.58 \\
\hline
\end{tabular}

\section{Conclusions}

IFT values were calculated for two types of linearhydrocarbon mixture models. A first type consisting of linear-hydrocarbon-water and the second type by linearhydrocarbon-glycerol mixtures. Additionally, IFTs were also estimated in eleven aqueous mixture systems with the organic liquids (ethyl acetate, n-butyl acetate, nitrobenzene, chloroform, glycerol, benzene, toluene, bromobenzene, methanol, iodobenzene, and cyclohexane). A total of 44 mixtures were evaluated considering different temperatures.

Results for mixtures of linear hydrocarbons with water show that theoretical IFT values closely follow the same general trend found with experimental and other theoretical data reported in the literature at different temperatures (22 and $50^{\circ} \mathrm{C}$ ). The errors were less than $4 \%$. The IFT increases with the increase of the $n$-alkane chain length. Also, for linear-hydrocarbon-glycerol mixtures systems, theoretically calculated values reproduced on average the experimental reported behavior with an average error less than 3.2\%.

In the case of the IFT results for immiscible organic liquids with water, calculated values were found to be quite similar to those reported in the literature and the average values. All deviations were lower than $4 \%$ except for error of Etact-W (18\%) and Chlrf-W (11\%) mixtures. The difference in these values could arise from the difference between the temperatures used in this work in relation to the ones reported.

It is valuable to mention that DPD-IFT results for linearhydrocarbon-water and -glycerol mixtures and for immiscible organic liquid-water mixtures give consistently good correlation with experimental and calculated values from the literature. This is particularly significant by taking into account that small systems with 3500 particles have been used and dynamics were carried out in a very short time period. Time lapses lower than 5 hours per each point of curves were handled for modeling mixtures. Additionally, each element of the system (molecule) was represented by a particle, thereby decreasing substantially the number of parameters to be considered to represent each mixture at the molecular level.

\section{Acknowledgements}

We are grateful to the engineer Gustavo Adolfo Guerrero Torelló, from Institute of Venezuelan Petroleum Technology (Intevep) for a review of this publication providing valuable corrections and suggestions. This work was supported by PVSA-Intevep.

\section{References}

[1] A. Narve. Dept of Chem. Eng. Norwegian Univ of Sci and Technol, Trondheim. 2002, 2-4. Retrieved from: http://www.firp.ula.ve/archivos/tesis/02_DR_Aaske.pdf.

[2] C del V. Silva. Universidad Central de Venezuela. Science Faculty. Physics Department, Venezuela. Retrieved from: http://190.169.94.51/cgi-

win/be alex.exe?Autor $=$ Silva, + Carolina + del + Valle $\&$ Nombreb $\mathrm{d}=$ bfcucv\&Sesion $=42729559 \&$ Opc $=$ FD_EST; $\&$ TipoDoc $=$ T.

[3] A. Goebel; K. Lunkenheime. Langmuir. 1997,13, 369-372. DOI: $10.1021 / \mathrm{la} 960800 \mathrm{~g}$.

[4] A. L. López de Ramos; S. Zeppieri; J. Rodríguez. J. Chem. Eng. 2001,46, 5, 1086-1088. DOI: 10.1021/je000245r.

[5] G. Wiegand; E. U. Franck. Phys. Chem. 1994, 98, 6, 809-81 7. DOI: $10.1002 /$ bbpc. 19940980608.

[6] Guo Tian-Min; Yang Ji-Tao; Cai Bi-Yu. J. Chem. Eng. Data. 1996, 41, 493-496. DOI: 10.1021/je950259a.

[7] H. Modarress; H. Rezaei. Chem. Phys. Lett. 2015, 620, 114 122. DOI:10.1016/j.cplett.2014.12.033.

[8] J. L. Rivera; C. McCabe; P. T. Cummings. Phys. Rev. E. 2003, 67, 011603. DOI: 10.1103/PhysRevE.67.011603.

[9] M. Alpbaz; A. Bilgesü; O Tutkun. Fac. Sci. Univ. Ank. Serie B. 1988, V 34, 103-112. Retrieved from: http://dergiler.ankara.edu.tr/dergiler/31/1438/16166.pdf.

[10] S. Majumdar; H. Goel; P. R. Chandran; K. Mitra; S. Majumdar; P. Ray. Chem. Phys. Lett. 2014, 600, 62-67. DOI: 10.1016/j.cplett.2014.03.061.

[11] Robert David. Colloids Surf. A. 2016, 498, 156-160. DOI: j.colsurfa.2016.03.055.

[12] M. H. Ghatee; H. Ghazipour. Fluid Phase Equilib. 2014, 377, 76-81. DOI: 10.1016/j.fluid.2014.06.018.

[13] A. H. Demond; A. S. Llndner. Environ. Sci. Technol. 1993, 27, 12, 2318-2331. DOI: 10.1021/es00048a004.

[14] K. Muijlwijk; E. Hinderink; D. Ershov; C. Berton-Carabin; K. Schroën. J. Colloid Interface Sci. 2016, 470, 71-79. DOI: 10.1016/j.jcis.2016.02.041.

[15] M. P. Andersson; F. Eckert; J. Reinisch; A. Klamt. Fluid Phase Equilib. 2017, 1-5. DOI: 10.1021/acs.jctc.6b00818.

[16] P. Ghosh. NPTEL. Chem. Eng. Interfacial Engineering. Consulted on 2017, Module 2, Lecture 2, 4-5. Retrieved from: http://nptel.ac.in/courses/103103033/8. 
[17] P. J. Hoogerbrugge; J. M. V. A. Koelman. Europhys. Lett. 1992, 19, 3, 155-160. Retrieved from: http://iopscience.iop.org/issue/0295-5075/19/3.

[18] P. Español; P. Warren. Europhys. Lett. 1995, 30, 4, 191-196. Retrieved from: http://iopscience.iop.org/issue/02955075/30/4.

[19] P. Español. Phys. Rev. 1996, 53, 2, 1572-1578. DOI: https://doi.org/10.1103/PhysRevE.53.1572.

[20] A. Maitia; S. McGrother. J. Chem. Phys. 2004,120, 3, 159416001. DOI: $10.1063 / 1.1630294$.

[21] F. A. Oseguera. Universidad Autónoma de San Luis de Potosí. Institute of Physics. San Luis Potosí, SLP, México. 2009, 7-9. Retrieved from: http://www.simes.uaemexlabs.org.mx/contrib/tesisKATM.pdf.

[22] M. del Mar. S. Maestro. Universidad Nacional de Educación a Distancia. Facultad de Ciencias. Departamento de Física Fundamental. Madrid, España. 2002, 4-9. Retrieved from: http://e-spacio.uned.es/fez/eserv/tesisuned:CienciasMmserrano/Documento.pdf.
[23] R. D. Groot; P. B. Warren. J. Chem. Phys. 1997, 107, 11, 4423-4435. Retrieved from:https://pdfs.semanticscholar.org/b2c1/94d6cbc3374e9f4f 2011d90f4c2e5dac09c1.pdf.

[24] C. M. Hansen. Hansen Solubility Parameters: A User's Handbook. CRC Press: Boca Raton, FL, ISBN: 0-8493-15255. 1999, 9-14

[25] M. Levin; Per Redelius. Energy Fuels. 2008, 22, 5, 33953401. DOI: 10.1021/ef800256u.

[26] S. Acevedo; A. Castro; E. Vásquez, F; Marcano; M. A. Ranaudo. Energy Fuels. 2010, 24, 5921-5933. DOI: 10.1021/ef1005786.

[27] Remington. Essentials of Pharmaceutics. First edition. Chapter 19. Pharmaceutical Press: 1 Lambeth High Street, London SE1 7JN. 2013, 330.

[28] J. N. Byrd; R. J. Bartlett; J. A. Montgomery. J. Phys. Chem. A. 2014, 118, 1706-1712. DOI: 10.1021/jp4121854. 